\title{
Holography demonstrations and workshops for science and engineering outreach
}

Weston Thomas, Kevin Kruse, Christopher Middlebrook

Weston Thomas, Kevin Kruse, Christopher Middlebrook, "Holography demonstrations and workshops for science and engineering outreach," Proc. SPIE 8481, Optics Education and Outreach II, 84810 S (15 October 2012); doi: $10.1117 / 12.930937$

EDIE Event: SPIE Optical Engineering + Applications, 2012, San Diego, California, United States 


\title{
Holography demonstrations and workshops for science and engineering outreach
}

\author{
Weston Thomas, Kevin Kruse, Christopher Middlebrook \\ Electrical Engineering, Michigan Technological University, Houghton, MI 49931
}

\begin{abstract}
The SPIE/OSA Student Chapter at Michigan Technological University have developed demonstrations and workshops for science and engineering outreach. The practical approach to holography promotes the study of photonic related sciences in high school and college-aged students. An introduction to laser safety, optical laboratory practices, and basic laser coherence theory is given in order to first introduce the participants to the science behind the holograms. The students are then able to create a hologram of an item of their choice, personalizing the experience. By engaging directly, the students are able to see how the theory is applied and also enforces a higher level of attention from them so no mistakes are made in their hologram. Throughout the course participants gain an appreciation for photonics by learning how holograms operate and are constructed through hands on creation of their own holograms. This paper reviews the procedures and methods used in the demonstrations and workshop while examining the overall student experience.
\end{abstract}

\section{INTRODUCTION}

An important aspect to a successful SPIE chapter is its ability to remain passionate in K-12 outreach activities. The Michigan Technological Chapter has a few different photonics demonstrations which can be used for such an outreach activity. The idea was to create a workshop type of event which could be used for middle school and higher level students. Holography was proposed for this event and this provides a visual aspect to the science and engineering concepts of the workshop.

The holography workshop was held for non-photonics based college students within the university. This served as a means to find tune the workshop details. High school outreach versions can commence as part of Michigan Tech's Summer Youth Programs (SYP). [1] SYP is an annual event held throughout the summer for various groups of high school level students with each session geared towards a different group. Two sessions were of particular interest, Women in Engineering (WIE) and Engineering Scholars Program (ESP). Each SYP session lasts for a week and consists of clinics in both the morning and afternoon. All of the workshops focus on a different specialization in engineering, science or mathematics. The SPIE/OSA Chapter [2] set up a holography workshop in collaboration with SYP as part of the electrical engineering department. It was organized and managed by SPIE/OSA student members. This is a great way to reach a large pool of high school students without having to organize a large scale event.

\section{HOLOGRAPHY: TECHNICAL ASPECTS}

The workshop aimed at college level students had the added benefit of illustrating what level of scientific explanation is conceptually acceptable for this level of education. Assuming most high schools students have not or have just begun basic physics, it placed a definitive cap on the technical aspects of the workshop. The focus was on making sure the students are able to understand the fundamental properties of light and how that applies towards holography and its applications. The first hologram type is a standard single illumination reflection hologram for display.

Optics Education and Outreach II, edited by G. Groot Gregory, Proc. of SPIE Vol. 8481

84810S · (c) 2012 SPIE · CCC code: 0277-786/12/\$18 · doi: 10.1117/12.930937 
The reflection holograms are made using Integraf's PFG-03M holographic plates and JD-4 developer (also referred to as the JARB processing regime [3]). A single HeNe laser expanded with a positive lens illuminates the hologram plate during exposure. An exposure time, of 30 seconds, was used in order to facilitate a lesser powered laser of $1.4 \mathrm{~mW}$. The lower power laser was chosen for safety reasons. The current setup, as shown in Figure 1, is located in a closed off optical laboratory. The procedure for development was determined by the hologram plate distributor as provided. [3] The first bath is the developer - a Metol/Sodium Carbonate and Sodium Hydroxide combination; followed by a distilled water dip. The second bath is a bleach solution - Copper Sulfate/Potassium Bromide - followed by another distilled water dip. Finally, the hologram is submerged in a solution to enhance drying without water spots or streaks. Hair dryers were not used due to the inability to filter out particles of dust and dirt that would decrease the image clarity of the hologram (this was tested prior to the start of the workshop).

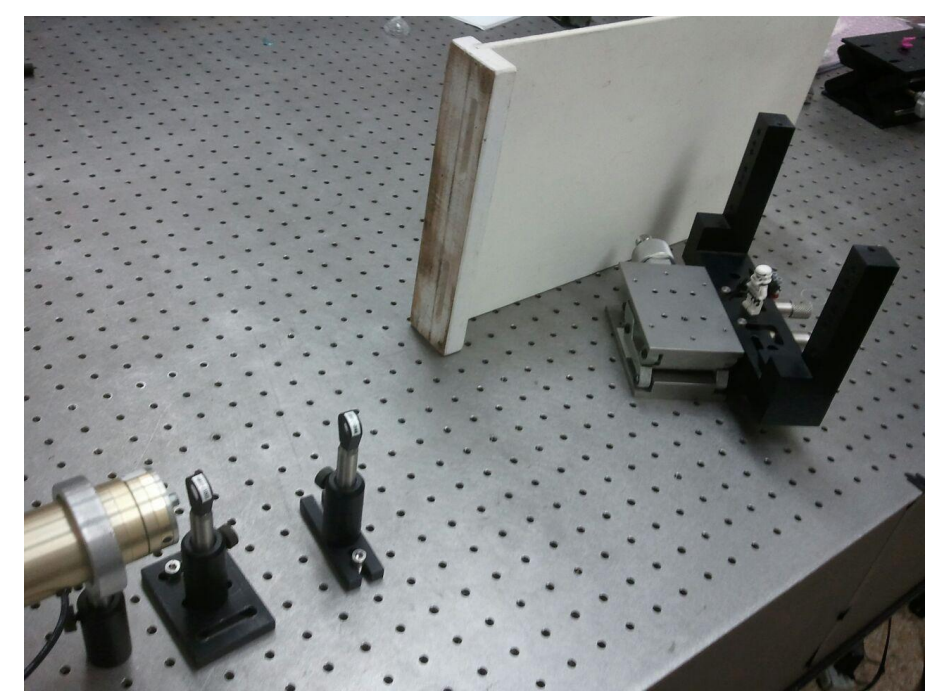

Figure 1: Current holography setup using $1.4 \mathrm{~mW}$ HeNe laser

Both styles of holography will focus on creating object images. Transmission holograms can be used to create diffraction gratings or interference patterns but this will not be part of the current experiments due to complexity in the optical setup. This means the image transmission holograms will only project for a small range due to the depth of field being produced. [4] The scientific focus was on the use of coherence to create an image from both a reference beam and an image. This can be discussed in various levels depending on the technical expertise of the participants.

\section{EVENTS}

The college level events were held throughout the spring semester. They focused just on creating neat looking reflection holograms. These were very small sessions and were also used for local chapter members to test out the process and make a holographic plate of their own. This was then followed by an open campus event as part of Engineering Week, a national event held to highlight engineering and sciences in universities. This allowed for non-electrical engineering students to participate and provide feedback. Everyone thought this event was quite enjoyable with numerous positive comments. A stand out reaction was from a business major who was quite surprised that this type of activity was occurring regularly on Michigan Tech campus. In all the participants appreciated the hands on approach and the 
ability to receive visual qualification of the procedure. An image of the objects available for hologram creation is shown in Figure 2 with a holographic image of a stormtrooper shown in Figure 3.

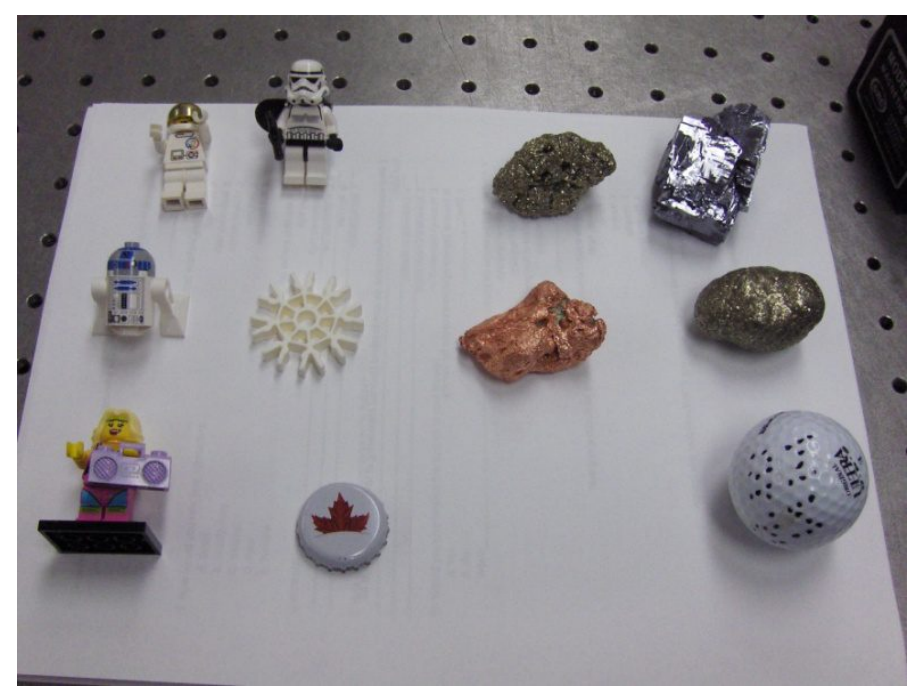

Figure 2: Objects used for hologram images

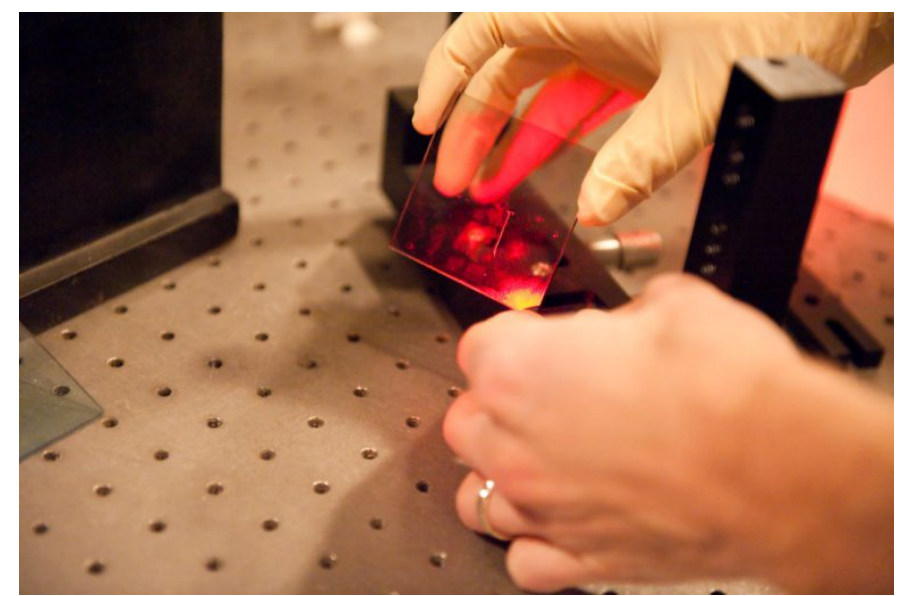

Figure 3: Completed hologram plate of stormtrooper (LEGO)

The LEGO figurines were excellent reflection hologram objects as they produce unique images with great detail. In contrast, the rocks make for fantastic looking projection holograms as they provide multiple glittering faces for imaging onto surfaces. The most important aspect for any of the objects is that they are able to convey the distinctive 3-dimensionality of the holographic process.

The SYP event lasts one week for each group of students. Within that week all students are given a chance to sign up for two projects. The project was titled "Holography in Medicine" which focused on holography with application into biomedical engineering. The first week of this SYP session was all young women who were currently sophomores and juniors in high school. There were 13 women in each of the two sections held for a total of 26. Each of the sections took one hour a day for 5 days. During those days we covered laser safety and holography introduction, reflection holograms, transmission holograms, hologram and photo development were covered. The last day was spent observing the finished holography plates and demonstrating applications to biomedical and electrical engineering. 
It was apparent from the beginning that the majority of participants signed up due to the biomedical nature of the project. They were in fact still interested in holography but were more interested in learning about applications towards biomedical engineering. This illustrates a fantastic benefit of holographic outreach; the ability to change application based on your target audience. It would seem young high school level females lean towards biomedical engineering or biological applications. The event can then be focused on demonstrating the use of optics and electrical engineering in biomedicine. Towards the end of the event more biomedical techniques other than just holography based were demonstrated to show off other applications of optics within the medical field. A favorite of the participants was the fluorescence demonstration illustrating how certain chemicals absorb ultraviolet light and re-emit it at a different wavelength as shown in Figures 4 \& 5.

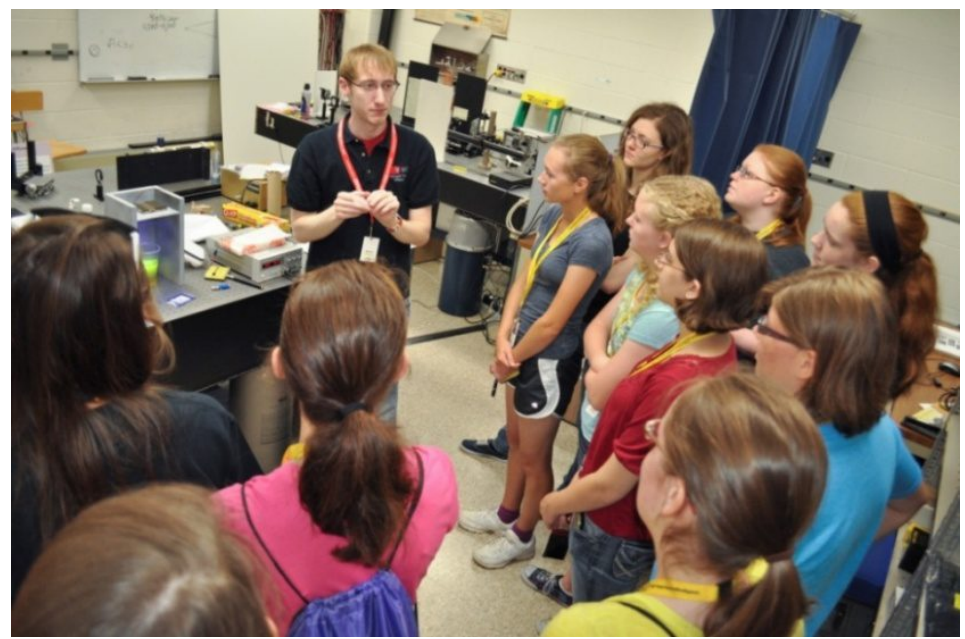

Figure 4: Women in engineering fluorescence demonstration

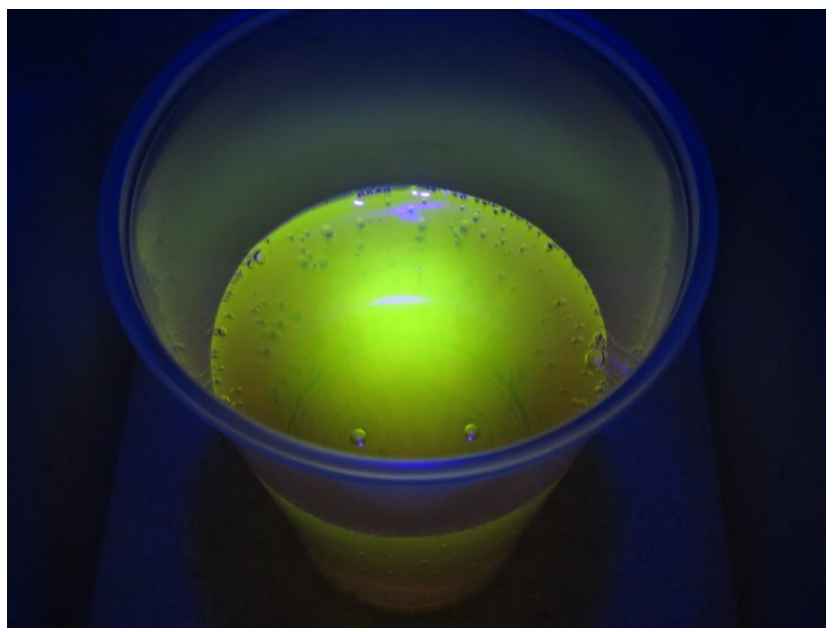

Figure 5: Close up of fluorescence demonstration

The second week of SYP was held for both male and female high school students interested in engineering, entitled as Engineering Scholars Program. Once again the optics project "Holography in Medicine" was available. While again the number one factor in the decision to attend the project was biomedicine most of the students seemed just as interested in general optics and holography. The integration of having boy and girl participants adds a slight complication as at that age they are more likely to talk amongst themselves instead of actively discussing the science of the project as desired. This 
was a small issue that was resolved most by continually bringing up new and interesting topics for them to think about and discuss. Similar demonstrations as the WIE session were shown including the fluorescence illustration. Another interesting note is that the level of education seemed slightly higher considering most if not all the students professed to having completed multiple AP (advanced placement) courses including Calculus and Physics. This meant a higher level of discussion concerning the creation of the holograms could be engaged.

\section{RESULTS AND STUDENT REACTION}

The college level was mostly used as demonstration and on campus recruiting for the local SPIE/OSA Student Chapter. The results and reactions of that outreach were mostly just discussion. The high school event was more structured and thus allowed for more numerical results. Surveys were provided to both sections at the beginning and end of the week. Results were separated by the two weeks available with first being the women's results. $70 \%$ of the participants of the women only session signed up primarily for the biomedical aspect with another 15\% interested in holography. In addition, 70\% of the participants claimed that they knew an adult close to them who worked in an engineering field. Shown here in Tables 1 thru 4 are graphs of a few of the more interesting results.

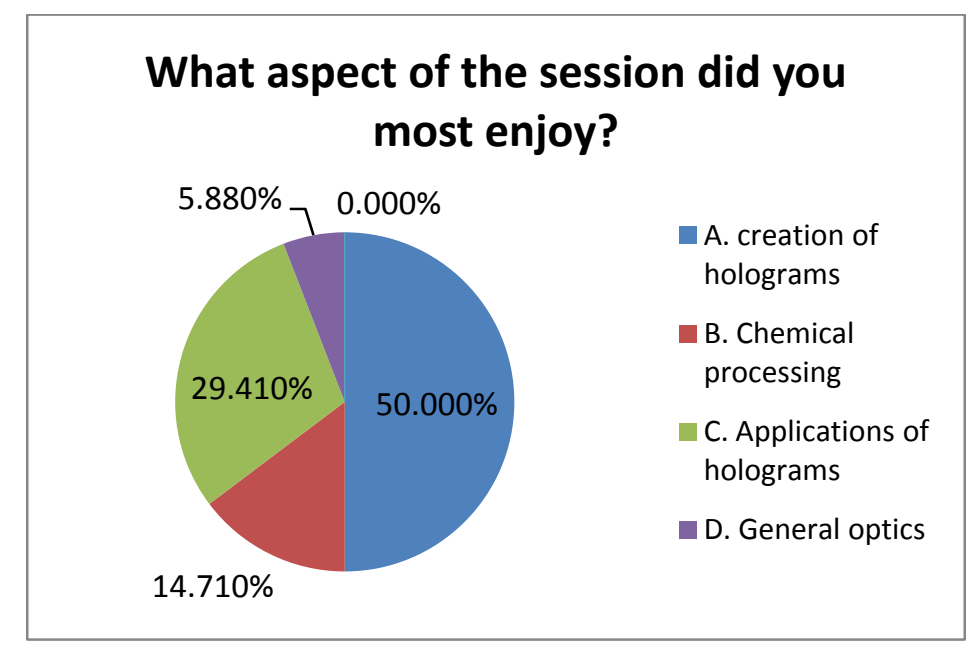

Table 1: Survey results from Women in Engineering 


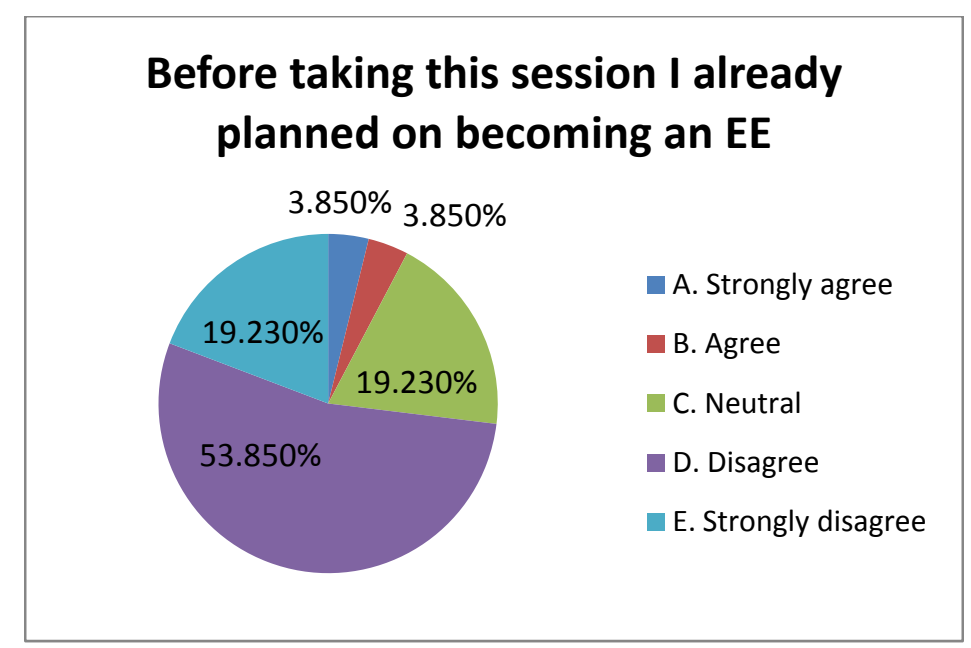

Table 2: Survey results from Women in Engineering

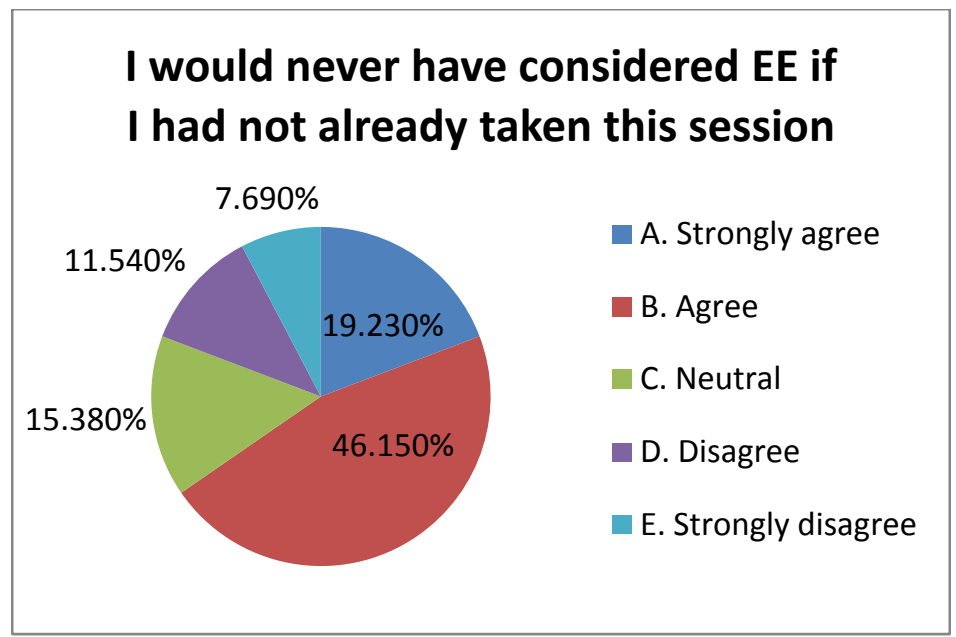

Table 3: Survey results from Women in Engineering session

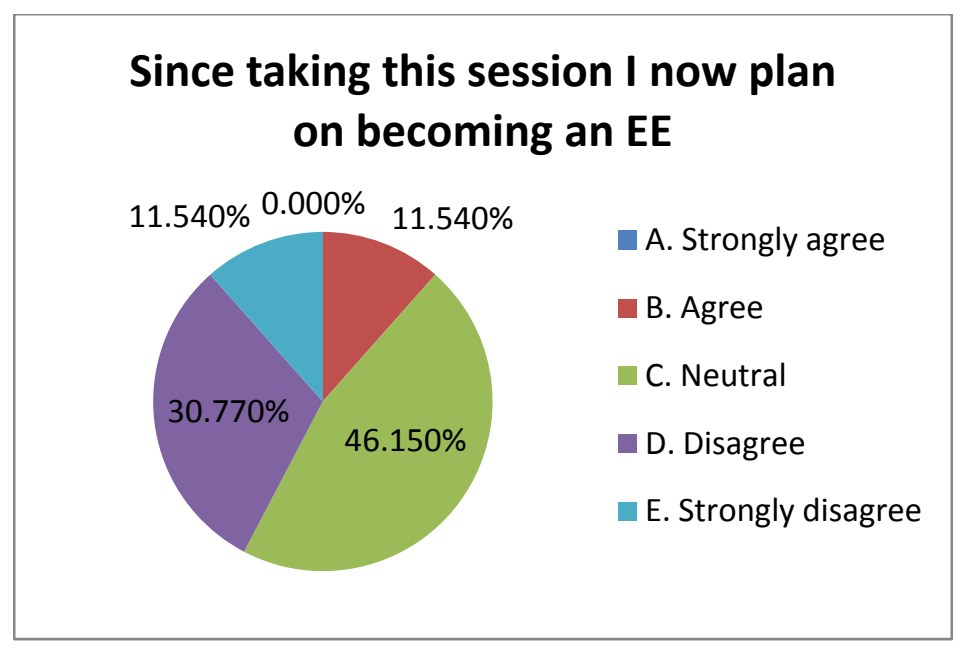

Table 4: Survey results from Women in Engineering session 
The session introduced these young women to electrical engineering and its ability to apply towards the medical field. This is an important result as it shows how application can be used positively to encourage people towards engineering fields. However, the second figure above illustrates that while many are now considering engineering they are not wholly sold on the discipline. This is still encouraging just not as definitive as would be liked.

The next week's session results while not wholly different were unique. The largest change was the interest in biomedicine. Only $42 \%$ of the participants signed up strictly for the biomedical nature of the project. Another $27 \%$ and $23 \%$ joined the project for the electrical engineering and holography creation aspect, respectively. In addition, $62 \%$ of the participants claimed to be in relation to an adult engineer matching up quite well with the women's only session. Tables 5 thru 8 as follows, are again of some interest in determining how well the session was received by the students.

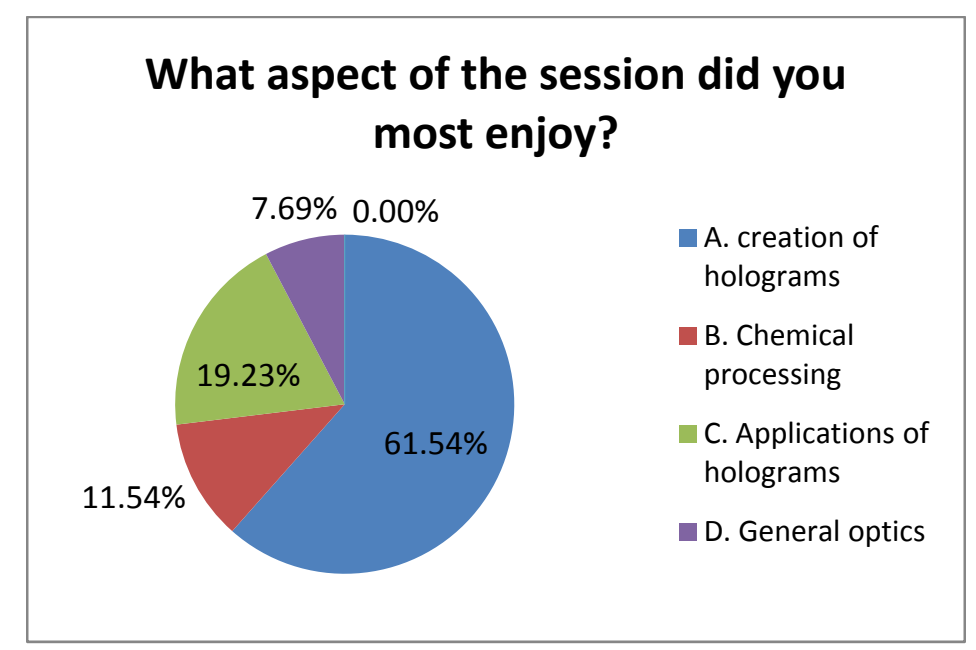

Table 5: Survey results from Engineering Scholars Program

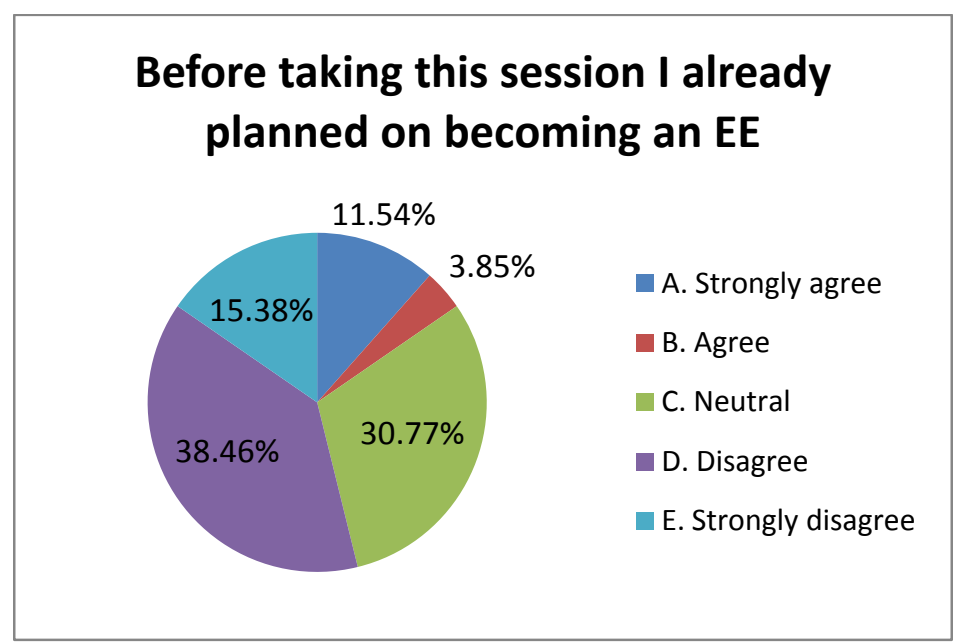

Table 6: Survey results from Engineering Scholars Program 


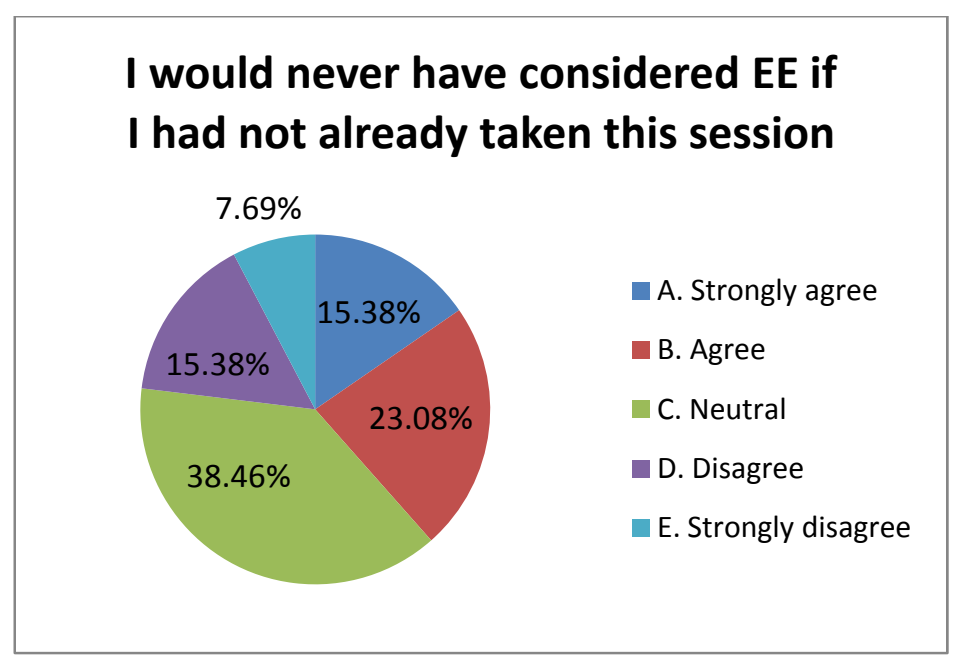

Table 7: Survey results from Engineering Scholars Program

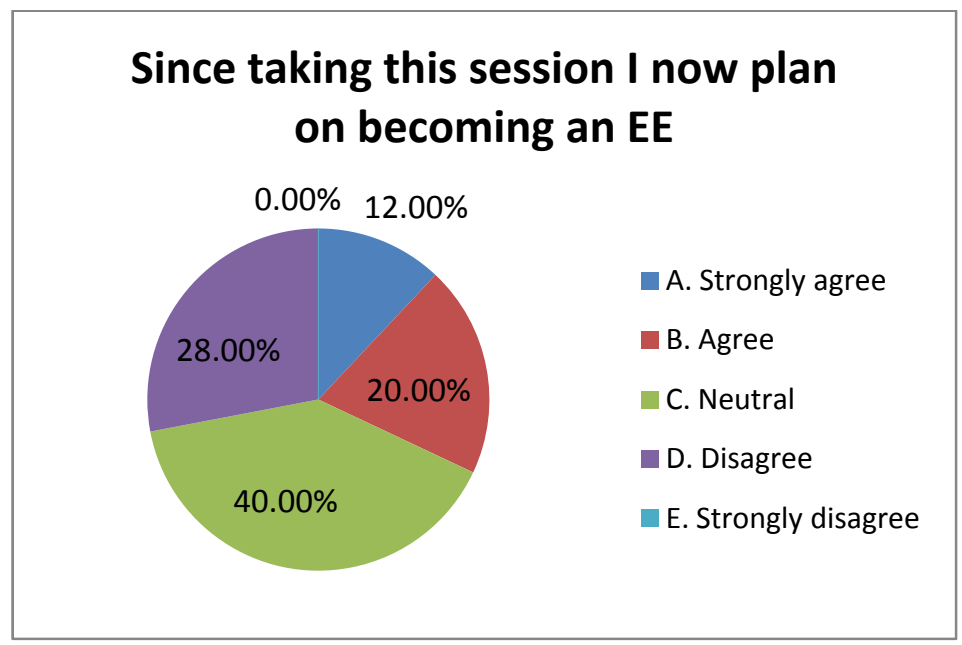

Table 8: Survey results from Engineering Scholars Program

In comparison with the WIE session the ESP session had more positive reactions towards EE as a possible discipline after the session. However, the women's session also had very seriously considering this as a possible path. The ESP session however had a very strong positive reaction for those on the fence concerning EE as a possible alternative to another engineering discipline. The hypothesis is that the leading factor for this change is a larger number of students came to the session with more openness concerning EE and holography instead of thinking only in terms of biomedicine. This is of interest for the continuing outreach towards high school aged students, specifically for optical and electrical engineering.

One of the most exciting parts of the session was when the students finally were able to view their finished plate. A large amount of patience was needed as they had a very difficult time determining which angle to view the hologram. Their reaction upon finally viewing the object of their making was very satisfactory. In addition, some miniaturized digital hologram sheets were given to demonstrate a secondary application and production mechanism. It also allowed students to show off a more detailed version of a hologram, something they could strive towards creating in the future. 


\section{CONCLUSION}

The creation of holography plates functions quite well as both a higher level technical demo and a high school workshop. It allows students interaction combined with unique visible effects (the laser!). Of course, with hands on demonstrations comes the downside of mistakes and results in non-effective hologram images. This problem can be overcome with back up images in case of errors but can be costly if large of number of students are involved with the workshops. The outreach capability is quite good if the workshop can be geared towards some application. This requires a knowledge project leader who is able to focus the participants who are not actively working on their hologram (unless a secondary setup is available so that creation can commence two at a time). The most important part of all of this is that the students really seemed to enjoy what they were doing. An entertaining science/engineering demonstration can make quite the difference for a student on the fence about his future prospects.

Special thanks to Jacob Carrick for his help in running the demonstration during the SYP event. Another special thanks to the members of SPIE/OSA Student Chapter at Michigan Tech for their participation in testing the hologram process and helping run the demonstrations for college aged students.

\section{REFERENCES}

[1] Michigan Technological University, "Michigan Tech Youth Programs - Summer Camps and Career Explorations," http://www.youthprograms.mtu.edu/students-prospective-syp.php (2011).

[2] Howard, Matthew, "SPIE Michigan Tech Student Chapter," http://spie.students.mtu.edu/ (2009).

[3] Integraf L.L.C., "Holographic Film, Kits, and Supplies to Make Holograms," http://www.integraf.com/ (2012).

[4] Saxby, Graham, Practical Holograph. Philadelphia, Institute of Physics: $3^{\text {rd }}$ ed., (2004).

[5] Goodman, J.W., Introduction to Fourier Optics. Englewood, Roberts and Company Publishing: $3^{\text {rd }}$ ed., (2005).

[6] Nave, C. R., "HyperPhysics Concepts - Holography," Georgia State University, http://hyperphysics.phy-astr.gsu.edu/hbase/optmod/holog3.html (2012). 